Original Article

\title{
Syntax Comprehension in 4-6 Year Old Foster Children
}

\author{
Ali Jafari Naimi ${ }^{1}$, Zohre Arani Kashani², Reyhane Mohamadi ${ }^{2 *}$, Mahboobeh Rasouli
}

1. MSc Student, Speech Pathology Department, Faculty of Rehabilitation Sciences, Iran University of Medical Sciences, Tehran, Iran

2. Assistant Professor, Speech Pathology Department of Speech \& Language Pathology, Faculty of Rehabilitation Sciences, Iran University of Medical Sciences (IUMS), Tehran, Iran

3. Assistant Professor, Department of Biostatistics, Faculty of Public Health, Iran University of Medical Sciences, Tehran, Iran

\begin{tabular}{c} 
Article Info \\
\hline Received: 2018/10/09 \\
Accepted: 2018/12/15 \\
Published Online: 2018/12/30
\end{tabular}

DOI: $10.30699 /$ fdisj.1.3.45

How to Cite This Article

Jafari Naimi A., Arani Kashani Z., Mohamadi R. Rasouli M. Syntax Comprehension in 4-6 Year Old Foster Children. Function and Disability Journal. 2018 (Autumn). Vol 1. No: 4. Pages: $45-53$

Use your device to scan and read the article online

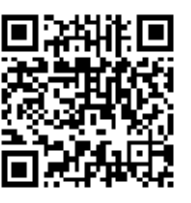

\section{ABSTRACT}

Background \& Objectives: The educational environment and family are of the most important factors in the growth and development of linguistic and verbal skills of a child. Certain conditions such as environment can influence the linguistic characteristics of the child. This study aimed to examine the syntax comprehension of Persian language speaking children among foster families and typically-developing children.

Methods: 72 Persian speaking children living in orphanages between the ages 4 to 6 and 75 typically-developing 4 to 6 year-old children were assessed by the Persian syntax comprehension test. This test measures 24 syntactic constructs of Persian language in 96 items. Also, the Mann-Whitney Test was used to compare the groups.

Results: Given the results of the Persian syntax comprehension test, the mean syntax compression score of children living in orphanages were significantly lower than those of typically-developing children $(P<0.05)$.

Conclusion:The foster children should be more paid attention to, in order to particularly enhance their syntax comprehension.

Keywords: Orphanage, Syntax comprehension, Language, Foster children, Typically-developing children

Copyright (C) 2018, Function and Disability Journal. This is an original open-access article distributed under the terms of the Creative Commons Attribution-noncommercial 4.0 International License which permits copy and redistribution of the material just in noncommercial usages with proper citation.

\section{Introduction}

The environment and specific conditions of the child's life are among the most important factors in the growth and development of linguistic and verbal skills. Although typically developing children progressively acquire linguistic skills quickly in a correct way, communications and behaviors of parents, caregivers and relatives can influence the process. Lack of any stimulation, motivation or encouragement of linguistic behaviors by the parent or child's caregivers will delay the growth of speech and language (Paul and Norbury, 2004; Eigsti and Cicchetti, 2004). Recent researches, which emphasize the importance of interacting with parents in the context of natural language acquisition, suggest that many factors affect this area, including verbal stimulation, parents' training styles, parent-child relationship and parents' personality attitudes and characteristics. The effective- 
ness of parents on children is mostly dependent on the frequency, duration, severity and quality of social contacts and their relationship with the children. Parents who are emotionally close to their children are more likely to affect their children compared to those who are not close to their children (Chen et al., 2012). Therefore, parents' behavioral and communicative patterns with the children can play an important role in their growth factors, such as speech and language development (Fox et al., 1988; Tayob and Moonsamy 2018). Developmental studies show that children are usually able to understand more than what they are able to produce, indicating complex syntactic constructions. Children can generally understand syntactic forms well before they begin to produce them (Fraser et al. 1963; Clark and Hecht 1983; Bates and Bretherton 1988).

Every year, parents leave a large number of children in society due to socio-economic pressures across the world (Simsek et al., 2007). The most common form of care for abandoned children around the world is caring inside the orphanage. Parents' death, physical and mental problems, parents' divorce, family and financial problems are some of the most important reasons for children to be orphaned (Fox et al., 1988; Simsek et al., 2007). Living in the orphanage and child care centers have, in some respects, even more restrictions compared to children living in deprived families, and such conditions lead to a negative impact on the status of the child's developmental and communicational aspects. In the United States, more than half a million children are estimated to live in orphanages (Miller et al., 2000). In Iran, according to the statistics offered by the Welfare Organization, the number of children living in orphanages has been increasing in the recent years. As of 1997, the number of children covered by the Welfare Organization was 2,564 , and this figure reached 10,000 children in 2003. In $2013,10,000$ to 12,000 foster children under the age of 18 were covered by the Welfare Organization. Around 6,000 of these are held at orphanages (Rezaeian et al., 2014). Similarly, international statistics suggest that an increasing number of children experience life in foster care centers, and estimates have shown that the number of foster children ranges from 2,000,000 to more than 8,000,000 (Fernandez \& Barth, 2011). Furthermore, foster children show very significant deficits in terms of intellectual and cognitive development (Moulson et al., 2010).

In addition, the linguistic development of children is particularly important in this context, which is the basis for growth in other cognitive, social and emotional aspects. The quality and quantity of children's linguistic interactions with parents and the home environment are considered as fundamental factors in creating opportunities for language development and minor language skills, such as using spatial and syntactic rules (Carter et al., 2009). Various studies have reported linguistic problems of poorly supervised and neglected children who are living in orphanages. They show that such children have lower levels of linguistic expression compared to typically-developing children, and the lexical richness of these children is very low and the mean length of made speeches (syntactic skill index) is much shorter than that of the typically-developing children (Mehdipour Shahrivar, 1999). In an investigation using checklist and continuous speech sample, the variables including number of sentences, the rate of use of communication tools, the mean extra-curricular training hours, and the ability to express words and verbs were compared between foster and typically-developing children. The results showed that the difference between the two groups of foster and typically-developing children is very significant in all cases (Law et al., 2017). These children also have a lower level of speaking and reception compared to children of the same age, their vocabulary richness is very low and their average speech length is much shorter, such that more than $50 \%$ of them suffer from speech and language problems (Fritz et al., 2017). Because of environmental degradation, children living in orphanages are much poorer in terms of perceptual and phonological skills compared to other children living in natural environments. studies show that more than 50 percent of orphan children suffer from linguistic and verbal delays. Also, it should be noted that the lower the age of entry into the nursing care environment, the higher the severity of linguis- 
tic damage (Glennen and Masters, 2002; Pears et al., 2011; Windsor et al., 2007; Bernard et al., 2017). In a study conducted on syntax structure (syntax complexity and comprehension) of the 5-years old children living in orphanages, results indicated linguistic delay in the understanding of vocabulary and expression of syntactic structures among such children (Eigsti and Cicchetti, 2004). Most recently, some studies have been conducted to examine language growth among the children living in orphanages (Stock and Fisher, 2006). For example, Desmarais et al., (2011) argue that sentence comprehension skills and the spatial working memory skills are poorer among orphans compared to those living with their family. However, no considerable studies have been done on Iranian orphans' syntax comprehension. This is while evidence suggests a general relationship between children's linguistic defects and such conditions as neglect of the parents or the children's orphanage environment. Accordingly, the present study was aimed to investigate syntax comprehension among 4-6 year-old orphans and typically-developing children. Given the importance of this issue, such studies will lead to a better recognition of syntax comprehension among children living in orphanages, and the results can considerably help speech and language pathologists, by that presenting better rehabilitation services for such children.

\section{Materials and Methods}

This study was a carried out in a cross-sectional design. Seventy-two 4 to 6 year-old children living in orphanages (Shobeir, Hazrat-e-Roghayyeh and Ameneh) were recruited. In the second group, seventy-five typically-developing 4 to 6 year-old children were randomly selected from kindergartens. Both, orphanages and kindergartens were introduced by the State Welfare Organization of Iran. The study was approved by the Ethical Committee of Iran University of Medical Sciences (Code number: IR.IUMS. REC.1397.067). A silent place was considered in the mentioned kindergartens and orphanages for conducting the test. The children's personal information questionnaire about the individual, family, medical and communication status of the children was completed during the first session by the caregivers of the orphanage and the parents (for typically-developing children), psychologist and physician. The criteria for age and language status of the children were also recorded in the personal information questionnaire, and the children fulfilling the research criteria were entered into the study. The inclusion criteria were having the age of 4 to 6 , being monolingual (Persian), being present in the orphanage for more than a year and lacking of neurological, developmental and structural diseases. The Persian syntax comprehension test was administered. The test was standardized in 2015 on 4364 to 6 year-old Persian-speaking children. This test measures 24 Persian syntactic structures by 96 items. The psychometric properties of the syntax comprehension test include: content validity and criterion validity of the test items which were 0.81 and 0.57 , respectively. Internal consistency for the entire test and active and passive sentences formation are $0.89,0.50$ and 0.38 , respectively. Also, the temporal stability for the entire test and active and passive sentences formation are $0.56,0.66$ and 0.58 , respectively (Mohamadi, 2015).

Also, after the appropriate communication between the examiner and the child, the mentioned test was described for each child, and then it was performed. At first, the picture handbook of the syntax comprehension test was put in front of the child, and the examiner expressed some sentences based on the form of the test. Next, the child pointed to the images related to the sentences. Then, a number of these images was recorded on the page of the answer sheet. At the end of the test, each child's score was recorded on the sheet. Each child's score in this test was between 0 and 24. The zero score means that the child has not correctly responded to any of the four items of the test. The score 24 means that all 4 items have the correct answer for all syntax constructs. In order to be sure, the digital voice recorder (Kingstone, DVR902) was used for reviewing the data, and the software SPSS version 22 was employed to analyze the data. Descriptive statistics including mean, standard deviation were presented. Also in analytic statistics, 
the Mann-Whitney Test was used.

\section{Results}

First of all, in order to check normality of the samples' distribution in terms the correct answers to the test, the Shapiro-Wilk test was used. Consequently, with a Sig. value of .000 and .001 respectively for foster and typically-developing children in terms of age and that of .000 and .059 in terms of correct answers, normal distribution was not obtained from samples. For this reason, the Mann-Whitney Test was employed.

The results of using this test can be seen in Table 1 .

Table 1. Mann-Whitney Test Results on correct answers of participants

\begin{tabular}{ccccccc}
\hline Group & $\begin{array}{c}\text { Number of } \\
\text { participants }\end{array}$ & $\begin{array}{c}\text { Mean } \\
\text { rank }\end{array}$ & P-value & Sum of rank & Range & Interquartile \\
\hline Foster children & 72 & 47.12 & .000 & 3392.50 & 16 & 5 \\
\hline $\begin{array}{c}\text { Typically-developing } \\
\text { Children }\end{array}$ & 75 & 99.81 & 7485.50 & 23 & 9 \\
\hline
\end{tabular}

As can be seen, the mean rank for correct answers of foster children (47.12) is significantly lower than that of typically-developing children (99.81). It is noteworthy to mention that foster children obtained the range and interquartile of 16 and 5, respectively, while typically-developing children found those of 23 and 9 , respectively.

As can be seen, 46 boys (56.1\%) and 26 girls $(40.0 \%)$ composed the foster children group and 36 boys (43.9\%) and 39 girls $(60.0 \%)$ constituted the typically-developing children group (Table 2).

Table 2. The participants'specifications separated by their gender obtained using the Chi-Square Test

\begin{tabular}{|c|c|c|c|c|c|}
\hline & & & \multicolumn{2}{|c|}{ Gender } & \multirow{2}{*}{ Total } \\
\hline & & & boy & girl & \\
\hline & \multirow{2}{*}{ Foster children } & Count & 46 & 26 & 72 \\
\hline & & $\%$ within gender & $56.1 \%$ & $40.0 \%$ & $49.0 \%$ \\
\hline & \multirow{2}{*}{ typically-developing children } & Count & 36 & 39 & 75 \\
\hline & & $\%$ within gender & $43.9 \%$ & $60.0 \%$ & $51.0 \%$ \\
\hline & Total & Count & 82 & 65 & 147 \\
\hline & vithin gender & $100.0 \%$ & $100.0 \%$ & $100.0 \%$ & \\
\hline
\end{tabular}

\section{Discussion}

Syntax is a language skill designated for supporting children's reading comprehension. Nevertheless, studies examining the children having average and below-average reading comprehension scores report inconsistent findings (Brimo et al., 2018). To the best of our knowledge, no Persian study has specifically investigated syntax comprehension of orphans. For such a limitation, the comparison was accomplished given the most similar findings in other works.

The results of the Mann-Whitney Test in the present study showed that foster children perform significantly poorer compared to typically-developing children in terms of syntax comprehension skills. This finding is consistent with the theoretical logic and some research evidence of similar studies including (Wind- 
sor et al., 2007) where the language growth among foster children was investigated and linguistic delays were found among them. Using the Goldman-Fristoe test of articulation complete kit and the Partial Least Square (PLS), the cognitive, expressive and speech skills of 74 orphan children were examined by Culp et al., (1991) and the results showed that such children demonstrate problems in all cognitive, speech and linguistic skills. Eigsti and Cicchetti (2004), using IPSyn and PPTV, investigated the syntactic complexity and vocabularies perception among 19 foster children who showed linguistic delay in percepting vocabularies and expressing syntactic constructs. In a comparison of environmental effects on mental and speech concepts among children living in orphanages, the following variables were investigated: 1) linguistic concepts, 2) mental concepts, 3) speech level and, 4) speech disorder. The results of the research showed that the difference between children living in orphanages and those typically-developing was very significant in all cases (Prelock et al., 2008).

Additionally, in a meta-analysis of 75 studies, van IJzendoorn et al. (2008) found that children living in orphanages scored an average of 20 points lower on intelligence tests compared to those living with their families. Mehdipour Shahrivar (1999) investigated among 305 to 6 year-old children living in Ameneh Orphanage and 305 to 6 year-old typicallydeveloping children using the test of understanding and expressing concepts and speech sampling in three situations, including describing the image, storytelling and dialogue, the properties mean speech length, complete and incomplete words and perception and expression of concepts. The results indicated that the complete words, incomplete words and mean speech length are lower among the former group and their mean score for understanding and expressing the linguistic concepts was also lower than typically-developing children. However, the former group members showed no problem on the synthetic level. Aslipoor et al., (2012) compared 15 children living in orphanages and 45 typically-developing children between the ages 2 and 6 in terms of speech capabilities using checklist and continuous speech sample. In doing so, the following variables were examined: 1) number of sentences, 2) the rate of using communication tools, 3) the mean extra-curricular training hours, and 4) the ability to express words. Results showed that the difference between the two groups of foster and typically-developing children is very significant in all cases. Furthermore, Mohamadi (2015) examined 24 syntactic constructs on 4364 to 6 year-old typicallydeveloping children and 154 to 6 year-old language impaired children using the syntax comprehension test. Their results indicated that the mean score of the 24 syntactic constructs differs significantly between the two mentioned groups. This is while with increased age, an increasing trend of syntax comprehension growth is seen among typically-developing children. In addition, the results from studies of foster children who were prenatally exposed to substances show similar deleterious effects, including alterations in salivary cortisol response following a social stressor (e.g., giving a speech and performing mental arithmetic aloud in front of unfamiliar judges) (Fisher et al., 2012).

Accordingly, several studies have shown that the absence of "mothering" appropriate social-emotional experience, and relationships with a few consistent caregivers are the main reasons for such shortages compared to typical children (Rutter, 2000). This is while most institutions are staffed with caregivers who work rotating shifts in rather bleak material conditions. Young children in institutional care have often been abandoned at birth or soon after because of poverty or parental instability. In some cases, the state may have intervened to remove young children from their parents' care. In this article, we argue that institutional care is structurally and psychologically at odds with what young children need and that we should work to develop alternatives for orphaned and abandoned children (Dozier et al., 2012). For this reason, a primary developmental task during early childhood is the formation of a positive and secure attachment relationship with a supportive caregiver. This process can be disrupted when children experience maltreatment from their caregivers and multiple foster placements. Three independent interventions for 
young foster children demonstrate that, when foster caregivers are given appropriate support and training, children can develop healthy emotion and behavior regulation and positive, secure social relationships (Dozier et al., 2008)

Besides, some studies show that the children who are residents of substandard orphanages also considerably witness delay in general behavioral development (e.g., Hunt et al., 1976; Kaler \& Freeman, 1994; Petersburg-USA Orphanage Research Team, 2005). However, those living in standard orphanages developed Stanford-Binet IQs typical of the children living with their parents (Petersburg-USA Orphanage Research Team, 2008).

\section{Conclusion}

In a nutshell, the findings of this study indicate that due to the delay in syntax comprehension among chil- dren living in orphanages, efforts of the practitioners and responsible persons in orphanages were not sufficient. Here, we face such constraints as the limited number of participants and the age range of children. Future studies are proposed to consider these cases, increasing the power of generalizability and richness of the obtained information. Also, they are proposed to compare the different ages of children.

\section{Acknowledgment}

We would also like to show our gratitude to the supervisors of Ameneh Orphanage and the kindergarten for sharing their pearls of wisdom with us during the course of this research.

\section{Conflict of Interest Statement}

The authors have no conflict of interest to declare.

ment Security. J Child Fam Stud, 21(3), 403-410.

Clark, E.V., \& Hecht, B.F. (1983). Comprehension, production, and language-acquisition. Annu Rev Psychol, 34,325-349.

Culp, E., Watkins, R.V., Lawrence, H., Letts, D., Kelly, D., \& Rice, M. (1991). Maltreated children's language and speech development: Abused, neglected, and abused and neglected. First Language, 11, 377-389.

Desmarais, C., Roeber, B. J., Smith, M. E., \& Pollak, S. D. (2011). Sentence comprehension in postinstitutionalized school-age children. Journal of speech, language, and hearing research, 55(1), 45-54.

Dozier, M., Peloso, E., Lewis, E., Laurenceau, J., \& Levine, S. (2008). Effects of an attachment-based intervention on the cortisol production of infants and toddlers in foster care. Development and Psychopathology, 20, 845-859.

Dozier, M., Zeanah, C. H., Wallin, A. R., \& Shauffer, C. (2012). Institutional Care for Young Children: Review of Literature and Policy Implications. Social issues and policy review, 6(1), 1-25.

Eigsti, I. M., \& Cicchetti, D. (2004). The impact of child maltreatment on expressive syntax at 60 months. Dev Sci, 
$7(1), 88-102$.

Fernandez, E., \& Barth, R. (2011). How Does Foster Care Work? International Evidence on Outcomes. London: Jessica Kingsley Publishers.

Fisher, P. A., Kim, H. K., Bruce, J., \& Pears, K. C. (2012). Cumulative effects of prenatal substance exposure and early adversity on foster children's HPA axis reactivity during a psychosocial stressor. International Journal of Behavioral Development, 36, 29-35.

Fox, L., Long, SH., \& Langlois, A. (1988). Patterns of language comprehension deficit in abused and neglected children. J Speech Hear Disord, 53(3), 239-44.

Fraser, J., Bellugi, U., \& Brown, R. (1963). Control of grammar in imitation, comprehension and production. $\mathrm{J}$ Verb Learn Verb Behav, 2,121-135.

Fritz, P., Kleinhans, A., Kuisle, F., Albu, P., Fritz-Kuisle, C., \& Alscher, M. D. (2017). Medical diagnosis as a linguistic game. BMC medical informatics and decision making, 17(1), 103.

Glennen, S. (2002). Typical and Atypical Language Development in Infants and Toddlers Adopted From Eastern Europe. American Journal of Speech-language Pathology, 11, 417-433.

Hunt, J. M., Mohandessi, K., Ghodssi, M., \& Akiyama, M. (1976). The psychological development of orphanagereared infants: Interventions with outcomes (Tehran). Genetic Psychology Monographs, 94, 177-226.

Kaler, S., \& Freeman, B. (1994). Analysis of environmental deprivation: Cognitive and social development in Romanian orphans. Journal of Child Psychology and Psychiatry, 35, 769-781.

Law, J., Charlton, J., Dockrell, J., Gascoigne, M., McKean, C., \& Theakston, A. (2017). Early Language Development: Needs, Provision, and Intervention for Preschool Children from Socioeconomically Disadvantaged Backgrounds. A Report for the Education Endowment Foundation. Education Endowment Foundation, 1-48.

Mehdipour, N. (1999). The effect environmental privation on development speech and language foster children centers. Master Thesis, Iran University of Medical Sciences.

Miller, P. M., Gorski, P. A., Borchers, D. A., Jenista, J. A., Johnson, C. D., \& Kaufman, N. D., ... (2000). Devel- opmental issues for young children in foster care: Committee on early childhood, adoption and dependent care. Pediatrics, 106, 1145-1150.

Mohamadi, R. (2015). Development and standardization of a syntax comprehension test for Persian 4-6 year old children [Thesis]. Tehran, Iran: University of Social Welfare and Rehabilitation Sciences.

Moulson, M. C., Westerlund, A., Fox, N. A., Zeanah, CH., $\&$ Nelson, C. A. (2009). The effects of early experience on face recognition: An event-related potential study of institutionalized children in Romania. Child Development, 80, 1039-1056.

Paul, R., Norbury, C., \& Gosse, C. (2018). Language disorders from infancy through adolescence: Listening, speaking, reading, writing, and communicating (5th ed). Maryland Heights, MO: Elsevier/Mosby.

Pears, K. C., Heywood, C. V., Kim, H. K., \& Fisher, P. A. (2011). Prereading Deficits in Children in Foster Care. School psychology review, 40(1), 140-148.

Prelock, P. A., Hutchins, T., \& Glascoe, F. P. (2008). Speech-Language Impairment: How to Identify the Most Common and Least Diagnosed Disability of Childhood. The Medscape Journal of Medicine, 10(6), 136.

Rezaeian, A., Niknejad Jalali, A., Behnam Vanashi, H. R., Ashrafzadeh, F., \& Rezaeian, M. (2014). Effect of a developmental stimulatory package on the fine motor development of the 1-12 months old, foster care children. Journal of North Khorasan University of Medical Sciences, 6(3), 513-523.

Rutter, M. (2000). Psychosocial influences: Critiques, findings, and research needs. Development and Psychopathology, 12, 265-296.

Simsek, Z., Erol, N., Oztop, D., \& Münir, K. (2007). Prevalence and predictors of emotional and behavioral problems reported by teachers among institutionally reared children and adolescents in Turkish orphanages compared with community controls. Children and youth services review, 29(7), 883-899.

St. Petersburg-USA Orphanage Research Team. (2008). The effects of early social-emotional and relationship experience on the development of young orphanage children. The St. Petersburg-USA Orphanage Research Team. 
Monographs of the Society for Research in Child Development, 73(3), vii-viii, 1-262, 294-5.

Stock, C. D., \& Fisher, P. A. (2006). Language delays among foster children: Implications for policy and practice. Child Welfare, 85(3), 445.

Tayob, F., \& Moonsamy, S. (2018). Caregivers' reading practices to promote literacy in a South African children's home: Experiences and perceptions. The South African journal of communication disorders, 65(1), e1-e9.
Van, I. J., zendoorn, M. H., Luijk, M., \& Juffer, F. (2008). IQ of children growing up in children's homes: A metaanalysis on IQ delays in orphanages. Merrill-Palmer Quarterly, 54, 341-366.

Windsor, J., Glaze, L. E., Koga, S. F., \& Bucharest Early Intervention Project Core Group. (2007). Language acquisition with limited input: Romanian institution and foster care. J Speech Lang Hear Res, 50(5), 1365-81. 


\section{بر رسى درك نحو در كودكان f تا \& سالة مقيم مركز نگگهدارى}

\section{على جعفرى نعيمى'، زهره آرانى كاشانى '، ريحانه محمدى זّ، محبوبه رسولى"}

$$
\begin{aligned}
& \text { I. دانشجوى كارشناسى ارشد، كروه كفتاردرمانى، دانشكدة علوم توانبخشى، دانشكاه علوم يزشكى ايران، تهران، ايران }
\end{aligned}
$$

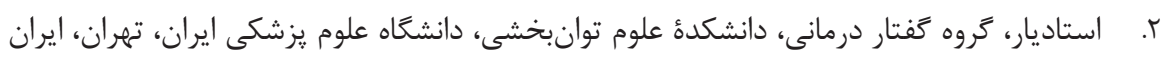

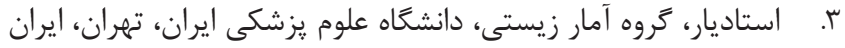

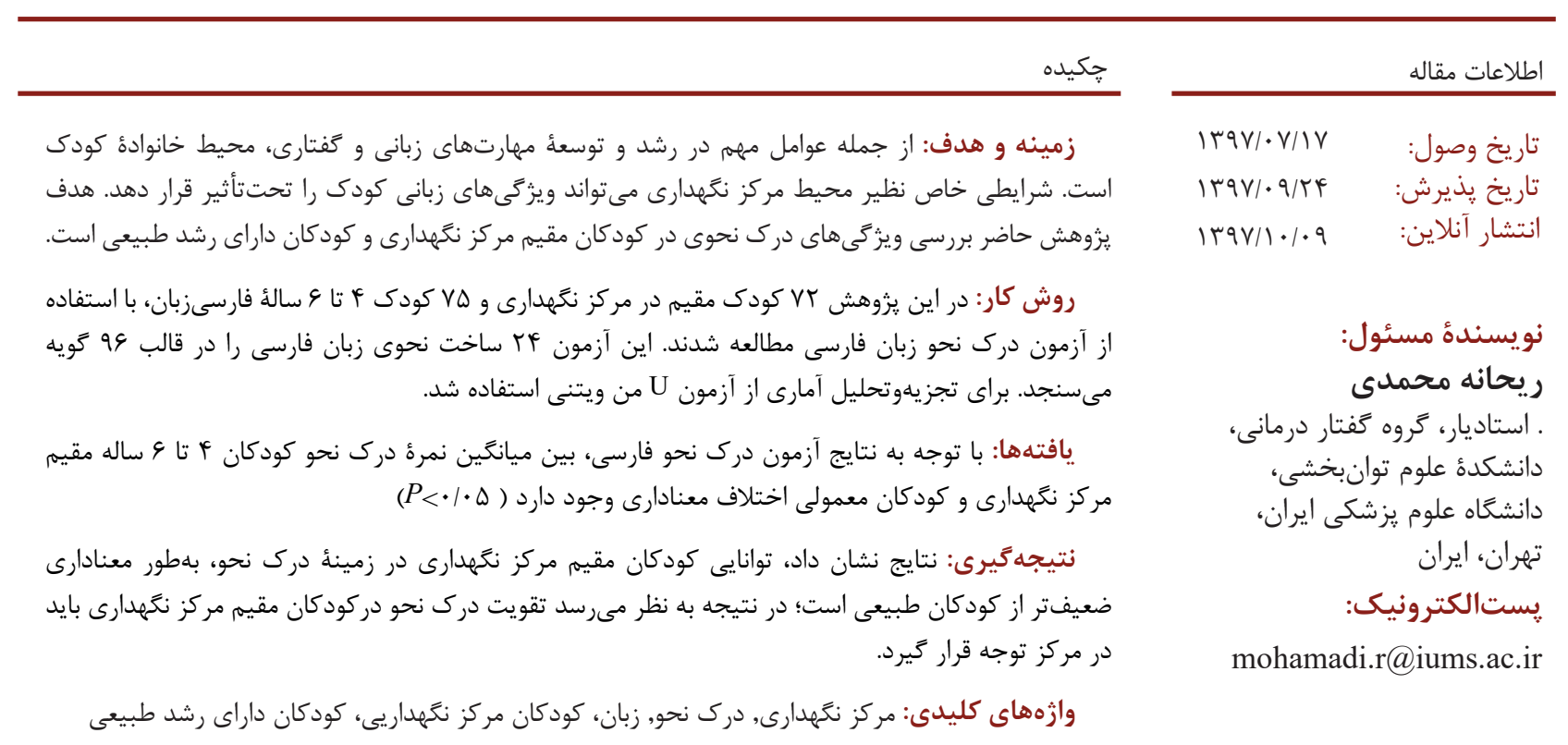

